\title{
Converging Cognitive Enhancements
}

\author{
ANDERS SANDBERG $^{a}$ AND NICK BOSTROM $^{b}$ \\ ${ }^{a}$ Oxford Uehiro Centre for Practical Ethics, Faculty of Philosophy, ${ }^{b}$ Oxford \\ Future of Humanity Institute, Faculty of Philosophy \& James Martin 21st \\ Century School, Oxford University, Oxford, OX1 1PT, United Kingdom
}

http://www.nickbostrom.com

\begin{abstract}
Cognitive enhancement, the amplification or extension of core capacities of the mind, has become a major topic in bioethics. But cognitive enhancement is a prime example of a converging technology where individual disciplines merge and issues transcend particular local discourses. This article reviews currently available methods of cognitive enhancement and their likely near-term prospects for convergence.
\end{abstract}

KEYWORDS: cognitive enhancement; cognition; intelligence; biotechnology; collective enhancement; mental training; converging technologies

\section{CONVERGING COGNITIVE ENHANCEMENTS}

There are few resources more useful than cognitive ability. While other resources are necessary or desirable, cognition enables them to be used for achieving personal goals. While there is little evidence that high intelligence causes happiness there appears to be ample evidence that low intelligence increases the risk for accidents, negative life events, and low income (Gottfredson 1997, 2004) while higher intelligence promotes health (Whalley and Deary 2001) and wealth. We also need better cognition in order to balance an increasingly complex society where information becomes more available and our actions have more far-reaching consequences (Heylighen 2002a, $2002 b)$. There may also be an intrinsic existential value in being able to perceive, understand, and interact well with the world.

Cognitive enhancement may be defined as the amplification or extension of core capacities of the mind through improvement or augmentation of internal or external information processing systems. Cognition in turn can be defined as the processes an organism uses to organize information. This includes both the acquisition of information (perception), selecting (attention), representing (understanding), and retaining (memory) information, and using it to guide behavior (reasoning and coordination of motor outputs). Interventions to improve cognitive function may be directed at any one of these core faculties.

Address for correspondence: Anders Sandberg, Oxford Uehiro Centre for Practical Ethics, Faculty of Philosophy, Oxford University, Littlegate House, 16/17 St. Ebbe's St. Oxford, OX1 1PT. United Kingdom. Voice: +44(0)1865-286877; fax: +44(0)1865-286886.

e-mail: anders.sandberg@philosophy.ox.ac.uk

Ann. N.Y. Acad. Sci. 1093: 201-227 (2006). (C) 2006 New York Academy of Sciences.

doi: 10.1196/annals.1382.015 
As cognitive neuroscience has advanced, the list of prospective internal, biological enhancements has steadily expanded (Farah et al. 2004). Yet to date, it is progress in information technology and cultural organization that has produced the most dramatic advances in our ability to process information. External hardware and software supports now routinely give human beings effective cognitive abilities that in many respects far outstrip those of our native minds, and institutions like peer review or markets.

There exists a long tradition in human-computer interaction dealing with cognitive enhancement, beginning with William Ross Ashby defining intelligence as the "power of appropriate selection," which could be technologically amplified similar to physical power (Ashby 1956). By offloading mental tasks to computers or embedding humans within a software context their cognitive functioning could be amplified (Licklider 1960). The aim was not artificial intelligence but rather amplifying human intelligence. The archetypal example of this approach is Douglas C. Engelbart's famous Augmenting Human Intellect, which defined the goal as:

By 'augmenting human intellect' we mean increasing the capability of a man to approach a complex problem situation, to gain comprehension to suit his particular needs, and to derive solutions to problems. Increased capability in this respect is taken to mean a mixture of the following: more-rapid comprehension, better comprehension, the possibility of gaining a useful degree of comprehension in a situation that previously was too complex, speedier solutions, better solutions, and the possibility of finding solutions to problems that before seemed insoluble. And by 'complex situations' we include the professional problems of diplomats, executives, social scientists, life scientists, physical scientists, attorneys, designers - whether the problem situation exists for twenty minutes or twenty years. We do not speak of isolated clever tricks that help in particular situations. We refer to a way of life in an integrated domain where hunches, cut-and-try, intangibles, and the human 'feel for a situation' usefully co-exist with powerful concepts, streamlined terminology and notation, sophisticated methods, and high-powered electronic aids.

Man's population and gross product are increasing at a considerable rate, but the complexity of his problems grows still faster, and the urgency with which solutions must be found becomes steadily greater in response to the increased rate of activity and the increasingly global nature of that activity. Augmenting man's intellect, in the sense defined above, would warrant full pursuit by an enlightened society if there could be shown a reasonable approach and some plausible benefits (Engelbart 1962).

An important insight was that it is not enough to improve just computer hardware and software, but psychological and organizational aspects have to be taken into account.

The cybernetic approach has in itself been technology independent by focusing on what is enhanced rather than the means of doing it. This unfortunately also causes disconnection from the richer social-ethical debate surrounding the other approaches, because they mostly take place within bioethics and medical ethics. 
Studying cognitive enhancement solely in terms of bioethics, computer supported intelligence amplification or nanomedicine, risks missing the key commonalities. Converging technologies give a framework to approach the commonalities between different forms of human enhancement, as well as a way to contrast their differences and potential for divergence.

Criticisms of enhancements are often stated in a technology-independent form yet when analyzed from a converging technologies perspective they often show strong assumptions about a particular kind of technology. Those that are truly technology independent, even if originating within in a narrow area such as the genetics discourse, on the other hand raise relevant challenges for broad areas.

\section{PHARMACEUTICAL BIOTECHNOLOGY}

Today there exist a broad range of drugs that can affect cognition. Stimulant drugs like nicotine and caffeine are traditionally and widely used to improve cognition. In the case of nicotine a complex interaction with attention and memory occurs (Warburton 1992; Newhouse et al. 2004; Rusted et al. 2005) while caffeine reduces tiredness (Lieberman 2001; Smith et al. 2003; Tieges et al. 2004).

Lashley observed in 1917 that strychnine facilitates learning in rats (Lashley 1917). Since then several families of memory-enhancing drugs affecting different aspects of long-term memory have been discovered. They range from stimulants (Soetens et al. 1993; Lee and Ma 1995; Soetens et al. 1995), nutrients (Foster et al. 1998; Korol and Gold 1998; Winder and Borrill 1998; Meikle et al. 2005), and hormones (Gulpinar and Yegen 2004) over cholinergic agonists (Iversen 1998; Power et al. 2003; Freo et al. 2005) and the piracetam family (Mondadori 1996) to ampakines (Ingvar et al. 1997; Lynch 1998) and consolidation enhancers (Lynch 2002). The earliest drugs were mainly nonspecific stimulants and nutrients. For example, during antiquity honey water, hydromel, was used for doping purposes. Glucose is the major energy source for the brain, which relies on a continuous supply to function. Increases in availability (either due to ingestion or stress hormones) improve memory (Wenk 1989; Foster et al. 1998). Stimulants enhance either by increasing the amount of neuron activity or by releasing neuromodulators, both factors which make the synaptic change underlying learning more likely.

The growing understanding of memory allowed the development of more specific drugs. Stimulating the cholinergic system, which appears to gate attention and memory encoding, was a second step. Current interest is focused on intervening into the process of permanent encoding in the synapses, which has been elucidated to a great extent and hence has become a promising target for drug development. The goal would be drugs that not just allow the brain to learn quickly but also facilitate selective retention of the information that has been learned. It is known that the above families of drugs can improve 
performance in particular memory tests. It is not yet known whether they also promote useful learning in real-life situations.

Pharmacological agents might be useful not only for increasing memory retention, but also for unlearning phobias and addictions (Pitman et al. 2002; Ressler et al. 2004; Hofmann et al. 2006). Potentially, the combination of different pharmacological agents administered at different times could allow users a more fine-grained control of their learning processes, and perhaps even the ability to deliberately select the contents of their memory.

Even common, traditional, and unregulated herbs and spices, such as sage, can improve memory and mood through chemical effects (Kennedy et al. 2006). While less powerful than those of dedicated cholinesterase inhibitors, such effects illustrate that attempts to control access to cognition-enhancing substances would be problematic. Even chewing gum appears to affect memory, possibly by heightening arousal or blood sugar (Wilkinson et al. 2002).

Working memory can be modulated by a variety of drugs. Drugs that stimulate the dopamine system have demonstrated effects, as do cholinergic drugs (possibly through improved encoding) (Barch 2004). Modafinil has been shown to enhance working memory in healthy test subjects, especially at harder task difficulties and for lower performing subjects (Muller et al. 2004). (Similar findings, of greater improvements among low performers were also seen among the dopaminergic drugs, and this might be a general pattern for many cognitive enhancers.) On a larger battery of tasks, modafinil was found to increase forward and backward digit span, visual pattern recognition memory, spatial planning, and reaction time/latency on different working memory tasks (Turner et al. 2003). The reason might be that modafinil enhances adaptive response inhibition, making the subjects evaluate a problem more thoroughly before responding to it, thereby improving performance accuracy. The working memory effects might hence be part of a more general enhancement of executive function. A few other drugs may also improve executive function (Elliott et al. 1997; Kimberg et al. 1997; Mehta et al. 2000). Given that these functions are closely linked to what is commonly seen as intelligence, they may be the first step toward true intelligence-enhancing drugs.

Modafinil was originally developed as a treatment for narcolepsy, and can be used to reduce the performance decrements due to sleep loss with apparently small side effects and risk of dependency (Teitelman 2001; Myrick et al. 2004). The drug improved attention and working memory in sleep-deprived physicians (Gill et al. 2006) and aviators (Caldwell et al. 2000). Naps are more effective in maintaining performance than modafinil and amphetamine during long $(48 \mathrm{~h})$ periods of sleep deprivation than during short $(24 \mathrm{~h})$, but naps followed by a modafinil dose may be more efficient than either individually (Batejat and Lagarde 1999). These results, together with hormones like melatonin that can control sleep rhythms (Cardinali et al. 2002), suggest that drugs can help shape sleep and alertness patterns to improve task performance under demanding circumstances. 
Creativity can also be affected pharmacologically. A study using alcohol demonstrated that a mild dose of alcohol could improve the results of a creative scientific process (Norlander and Gustafson 1996). The improvement only occurred when the subjects got the alcohol during the "incubation phase" of the creative process, the period when they were not actively working on the problem but presumably their unconscious might have been active. Giving alcohol in a picture-drawing task during the later verification phase did not promote creativity (Norlander and Gustafson 1997).

Creative thinking does not just include divergent and disinhibited thinking, but also requires convergent thinking to focus on the realization of the insight (Cropley 2006). Excessive divergence or lack of inhibition may be similar to the situation in attention deficit hyperactivity disorder (ADHD). Adult ADHD individuals show a profile of divergent thinking and do badly on convergent thinking and inhibition tasks (White and Shah 2006). Hence medications affecting ADHD might promote convergent thinking. Methylphenidate, the most common treatment and a potential executive function enhancer, did not appear to impair flexible thinking in ADHD individuals (Solanto and Wender 1989; Douglas et al. 1995). Giving L-dopa, a dopamine precursor, to healthy volunteers did not affect direct semantic priming (faster recognition of words directly semantically related to a previous word, such as "black-white") but did inhibit indirect priming (faster recognition of more semantically distant words, such as "summer-snow") (Kischka et al. 1996). This was interpreted by the authors of the study as dopamine inhibiting the spread of activation within the semantic network, that is, a focusing on the task.

There also exist drugs that influence how the cerebral cortex reorganizes in response to damage or training. Noradrenergic agonists, such as amphetamine, have been shown to promote faster recovery of function after a brain lesion when combined with training (Gladstone and Black 2000) and to improve learning of an artificial language (Breitenstein et al. 2004). A likely explanation is that higher excitability increases cortical plasticity, in turn leading to synaptic sprouting and remodeling (Stroemer et al. 1998; Goldstein 1999). An alternative to pharmacological increase of neuromodulation is to electrically stimulate the neuromodulatory centers that normally control plasticity through attention or reward. In monkey experiments this produced faster cortical reorganization (Kilgard and Merzenich 1998; Bao et al. 2001).

In general, pharmacological enhancement is possible here and now, although the improvements in ability tend to be a modest $10-20 \%$ improvement of test scores. As for all pharmacology, there are great interindividual variations. Using enhancer drugs optimally might include tests of neuromodulator levels to see where the brain setpoints are, pharmacogenomic tests to find how they are metabolized and neuropsychological tests to check what levels produce maximum performance. Such fine-tuning is expensive and cumbersome unless it can be automated. 


\section{OTHER BIOTECHNOLOGIES}

Transcranial magnetic stimulation (TMS) stimulates neurons in the cerebral cortex by a changing magnetic field induced from a coil held to the head. It can increase or decrease the excitability of the cortex, thereby changing its level of plasticity (Hummel and Cohen 2005). TMS of the motor cortex that increased its excitability improved performance in a procedural learning task (PascualLeone et al. 1999). TMS in suitable areas has also been found beneficial in a motor task (Butefisch et al. 2004), motor learning (Nitsche et al. 2003), visuomotor coordination tasks (Antal et al. 2004a, 2004b), working memory (Fregni et al. 2005), finger sequence tapping (Kobayashi et al. 2004), classification (Kincses et al. 2004), and even declarative memory consolidation during sleep (Marshall et al. 2004). Snyder et al. demonstrated how TMS inhibiting anterior brain areas could change the drawing style of normal subjects into a more concrete style and improve spell-checking abilities, presumably by reducing top-down semantic control (Snyder et al. 2003, 2004). While TMS appears to be highly versatile and noninvasive, there are risks of triggering epileptic seizures and the effects of long-term use are not known. Individual brain differences may necessitate much adjustment before it can be applied to a specific use.

Genetic memory enhancement has been demonstrated in rats and mice. In normal animals, during maturation expression of the NR2B subunit of the $N$ methyl-D-aspartate (NMDA) receptor is gradually replaced with expression of the NR2A subunit, something that may be linked to the lower brain plasticity in adult animals. Tsien's group (Tang et al. 1999) modified mice to overexpress the NR2B. The NR2B "Doogie" mice demonstrated improved memory performance, both in terms of acquisition and retention. This included unlearning of fear conditioning, which is believed to be due to the learning of a secondary memory (Falls et al. 1992). The modification also made the mice more sensitive to certain forms of pain, suggesting a nontrivial trade-off between two potential enhancement goals (Wei et al. 2001).

Increased amounts of brain growth factors (Routtenberg et al. 2000) and the signal transduction protein adenylyl cyclase (Wang et al. 2004) have also produced memory improvements. These modifications have different enhancing effects: unlearning took longer for these modified mice than for unmodified mice, while the mice in the Tsien study had faster than normal unlearning. Different memory tasks were also differently affected: the cyclase mice had enhanced recognition memory but not improved context or cue learning. A fourth study showed that mice with a deleted $c b l-b$ gene had normal learning but enhanced long-term retention, presumably indicating that the gene is a negative regulator of memory (Tan et al. 2006). These enhancements may be due to changes in neural plasticity during the learning task itself, or that the developing modified brain develops in a way that promotes subsequent learning or retention. 
The cellular machinery of memory appears to be highly conserved in evolution, making interventions demonstrated to work in animal models likely to have close counterparts in humans (Edelhoff et al. 1995; Bailey et al. 1996).

Genetic studies have also found genes in humans whose variations account for up to 5\% of memory performance (de Quervain and Papassotiropoulos 2006). These include the genes for the NMDA receptor and adenylyl cyclase that were mentioned above, as well as other parts of the synaptic signal cascade. These are clear targets for enhancement.

Given these early results, it seems likely that there exist many potential genetic interventions that directly or indirectly improve aspects of memory. If it turns out that the beneficial effects of the treatments are not due to changes in development, then presumably some of the effects can be achieved by supplying the brain with the substances produced by the memory genes without resorting to genetic modification. But genetic modification would make the individual independent of an external drug supply and would guarantee that the substances end up in the right place.

On the other hand, studies of the genetics of intelligence suggests that there is a large number of genetic variations affecting individual intelligence, but each accounting for only a very small fraction $(<1 \%)$ of the variance between individuals (Craig and Plomin 2006). This would indicate that genetic enhancement of intelligence through direct insertion of a few beneficial alleles is unlikely to have a big enhancing effect. It is possible, however, that some alleles that are rare in the human population could have larger effects on intelligence, either negative or positive. A possible example is the prediction that heterozygoticity for Tay-Sachs' disease should increase IQ by about 5 points (Cochran et al. 2006).

While human germline engineering is controversial, several years away and likely to be expensive, the genetic discoveries discussed here may be used for enhancement in other ways. Gene expression may be affected pharmacologically or even through food intake.

A notable form of chemical enhancement is pre- and perinatal enhancement through maternal nutrition. Administering choline supplementation to pregnant rats improved the performance of their pups, apparently as a result of changes in neural development in turn due to changes in gene expession (Meck et al. 1988; Meck and Williams 2003; Mellott et al. 2004). Given the ready availability of choline supplements, such prenatal enhancement, may already (inadvertently) be taking place in human populations. Supplementation of a mother's diet during late pregnancy and 3 months postpartum with long-chained fatty acids has also been demonstrated to improve cognitive performance in human children (Helland et al. 2003). Deliberate changes of maternal diet may hence be seen as part of the cognitive enhancement spectrum. At present, recommendations to mothers are mostly aimed at promoting a diet that avoids specific harms and deficits, but the growing emphasis on boosting "good fats" and the use of enriched infant formulas point toward enhancement. 


\section{COGNITIVE TECHNOLOGY}

Education has many benefits beyond higher job status and salary. Longer education reduces the risks of substance abuse, crime, and many illnesses while improving quality of life, social connectedness, and political participation (Johnston 2004). There is also positive feedback between performance on cognitive tests, such as IQ tests and scholastic achievement, producing a 2.7 IQ point advantage per year of schooling (Winship and Korenman 1997). While education may be more of a social enhancement technology than a cognitive enhancement technology, it clearly has some potential for the latter.

Much of what we learn in school is "mental software" for managing various cognitive domains: mathematics, categories of concepts, language, and problem solving in particular subjects. This kind of mental software reduces our mental load through clever encoding, organization, or processing. Instead of memorizing arbitrarily large multiplication tables we compress the pattern of arithmetic relationships into simpler rules of multiplication, which in turn (among very ambitious students) can be organized into efficient mental calculation methods like the Trachtenberg system (Trachtenberg 2000). Such specific methods have a smaller range of applicability but can dramatically improve performance within a particular domain. They represent a form of crystallized intelligence, distinct from the fluid intelligence of general cognitive abilities and problem solving capacity (Cattell 1987). The relative ease and utility of improving crystallized intelligence and specific abilities have made them popular targets of internal and external software development. Cognitive enhancement attempts the more difficult challenge of improving fluid intelligence.

The challenge of improving education is perennial, and much hope is currently placed on using the results of neuroscience to improve education. However, so far pure neuroscience has provided few directly applicable tools (Goswami 2006). While this may change, the deep interdisciplinary divide that has to be bridged may prove a far greater challenge than most forms of technological convergence.

Pharmacological cognitive enhancements (nootropics) have physiological effects on the brain. So too do education and other conventional interventions. In fact, conventional interventions often produce more permanent neurological changes than do drugs. Learning to read alters the way language is processed in the brain (Petersson et al. 2000). Enriched rearing environments have been found to increase dendritic arborization and to produce synaptic changes, neurogenesis, and improved cognition in animals (Walsh et al. 1969; Greenough and Volkmar 1973; Diamond et al. 1975; Nilsson et al. 1999). While analogous controlled experiments cannot easily be done for human children, it is very likely that similar effects would be observed. Stimulation-seeking children, who might be seeking out and creating enriched environments for themselves, score higher on IQ tests and do better at school than less stimulation-seeking children (Raine et al. 2002). This also suggests that interventions that make 
exploring and learning more appealing to children, whether environmental or perhaps pharmaceutical, would have significant cognition-enhancing effects.

Enriched environments also make brains more resilient to stress and neurotoxins (Schneider et al. 2001). Reducing neurotoxins and preventing bad prenatal environments are simple and widely accepted methods of increasing cognitive function. These latter kinds of intervention might be classified as preventative or therapeutic rather than enhancing, although the distinction is blurry. For instance, an optimized intrauterine environment will not only help avoid specific pathology and deficits but is also likely to promote the growth of the developing nervous system in ways that ultimately enhance its core capacities.

In brains that have already been damaged, for example, by lead exposure, nootropics may alleviate some of the cognitive deficits (Zhou and Suszkiw 2004). It is not always clear whether they do this by curing the damage or by amplifying (enhancing) capacities that can compensate for the loss, or even whether the distinction is always meaningful. Comparing chronic exposure to cognition-enhancing drugs with an enriched rearing environment, one study found that both conditions improved memory performance and produced similar changes in the neural matter in rats. The improvements in the drug-treated group persisted even after cessation of treatment. The combination of drugs and enriched environment did not improve the rats' abilities beyond the improvement provided by one of the interventions alone. This suggests that both interventions produced a more robust and plastic neural structure able to learn more efficiently.

Improving general health has cognition-enhancing effects. Many health problems act as distractors or directly impair cognition (Schillerstrom et al. 2005). Improving sleep, immune function, and general conditioning promotes cognitive functioning. Bouts of exercise have been shown to temporally improve various cognitive capacities, the size of the effect depending on the type and intensity of the exercise (Tomporowski 2003). Long-term exercise also improves cognition, possibly by a combination of increased blood supply to the brain and the release of nerve growth factors (Vaynman and Gomez-Pinilla 2005). Understanding this system may lead to new classes of nootropics, perhaps as a side effect of research into regenerative medicine.

Overall, improvements in the environment may be effective and widely acceptable cognition enhancers, and conversely enhancement may help deprived individuals.

\section{MENTAL TRAINING}

Mental training and visualization techniques are widely practiced in elite sport (Feltz and Landers 1983) and rehabilitation (Jackson et al. 2004), with apparently good effects. Users vividly imagine themselves performing a task 
(running a race, going to a store), imagining every movement and how they feel again and again. A likely explanation for the efficacy of such exercises is that they activate the neural networks involved in executing a skill at the same time as the performance criteria for the task is held in close attention, optimizing neural plasticity and appropriate neural reorganization/ learning.

Even general mental activity, "working the brain muscle" can improve performance (Nyberg et al. 2003) and long-term health (Barnes et al. 2004), as can relaxation techniques to regulate the activation of the brain (Nava et al. 2004). It has been suggested that the Flynn-effect (Flynn 1987), a secular increase in raw intelligence test scores by 2.5 IQ points per decade in most western countries, can be attributed to increased demands of certain forms of abstract and visuospatial cognition in modern society and schooling, although improved nutrition and health status may also play a part (Neisser 1997; Blair et al. 2005). It appears that most of the Flynn effect does not reflect an increase in general fluid intelligence but rather a change in which specific forms of intelligence are developed.

The classic form of cognitive enhancement software is learned strategies to memorize information. Such methods have been used since antiquity with much success (Yates 1966; Patten 1990). One such classic strategy is "the method of loci." The user imagines a building, either real or imaginary, and in her imagination she walks from room to room, and places imaginary objects that evoke natural associations to the subject matter that she is memorizing. During retrieval, the user retraces her steps and the sequence of memorized information is recalled when she "sees" the objects she has placed along the route. This technique harnesses the brain's spatial navigation system to help remember objects or propositional contents. Other memory techniques makes use of rhyming or the fact that we more easily recall dramatic, colorful, or emotional scenes, which can serve as placeholders for items that are more difficult to retain, such as numbers or letters. The early memory arts were often used as a substitute for written text or to memorize speeches. Today, memory techniques tend to be used in service of everyday needs, such as remembering door codes, passwords, shopping lists, and by students who need to memorize names, dates, and terms when preparing for exams (Lorrayne 1996; Minninger 1997).

One study which compared exceptional memorizers (participants in the World Memory Championships) with normal subjects found no systematic differences in brain anatomy (Maguire et al. 2003). However, activity during encoding was different, likely reflecting the use of a deliberate encoding strategy. Especially areas of the brain involved in spatial representation and navigation were found to be consistently activated in the memorizers, regardless of whether the subjects were learning numbers, faces, or snowflakes. When asked about their memory strategies, nearly all memorizers reported using the method of loci. 
In general it appears possible to attain very high memory performance on specific types of material using memory techniques. They work best on otherwise meaningless or unrelated information, such as sequences of numbers, but do not appear to help skilled everyday activities (Ericsson 2003).

There also exists a vast array of mental techniques alleged to boost various skills, such as creativity training, speed reading methods (Calef et al. 1999), and mind-maps (Buzan 1982; Farrand et al.2002). It is unclear how widespread such techniques are, and good data regarding their efficacy is often lacking. Even if a technique improves performance on some task under particular conditions that does not necessarily mean that the technique is practically useful. In order for a technique to significantly benefit a person, it would have to be effectively integrated into her everyday work.

Of the mental training techniques, visualization may have the greatest potential for future development. While new memory arts can be developed the need for them is limited thanks to easily accessible external storage (the main exception may be remembering passwords). Serious studies of the efficiency of other mental techniques may be worthwhile. However, their specificity to particular tasks limits them. Methods of taking advantage of brain reorganization, possibly enhanced through nootropics and/or virtual reality training, appear to have general utility.

\section{INFORMATION TECHNOLOGY}

External hardware is of course already used for cognitive enhancement, be it pen and paper or computer software like personal organizers. This section can only scratch at the surface of the vast range of information technologies that have a cognitive enhancement function. There is practically no cognitive area where there does not exist external hardware or software amplification.

Many common pieces of software act as cognition-enhancing environments where the software helps give an overview, keep multiple items in memory, and perform routine tasks. Data mining and information visualization tools help produce overview and understanding where the perceptual system cannot handle the amount of data, while specialized tools like expert systems, symbolic math programs, decision support tools, and search agents expand specific skills and capacities.

What is new is the growing interest in creating intimate links between the external systems and the human user through better interaction. The software becomes less an external tool and more of a mediating "exoself." This can be achieved through mediation, embedding the human within an augmenting "shell," such as wearable computers (Mann 2001; Mann and Niedzviecki 2001) or virtual reality, or through smart environments, where capabilities of objects in the environment are extended. An example is the ubiquitous computing vision, in which objects would be equipped with unique identities and given 
ability to communicate with and to support the user (Weiser 1991). A welldesigned environment can enhance proactive memory (Sellen et al. 1996) by deliberately bringing previous intentions to mind in the right context.

Another form of memory-enhancing exoself software is remembrance agents (Rhodes and Starner 1996), agents that act as a vastly extended associative memory. The agents have access to a database of previous information, such as a user's files, e-mail correspondence, etc., and suggest relevant documents based on the current context. Other exoself applications include additions to vision (Mann 1997), team coordination (Fan et al. 2005a, 2005b), face recognition (Singletary and Starner 2000), mechanical prediction (Jebara et al. 1997), and recording emotionally significant events (Healey and Picard 1998).

Given the availability of external memory support, from writing to wearable computers, it appears likely that the crucial form of memory demand will be the ability to link together information into usable concepts and associations rather than storage and retrieval of raw data. Storage and retrieval functions can be offloaded to a great extent from the brain, while the knowledge, strategies, and associations linking the data to skilled cognition so far cannot generally be offloaded.

Wearable computers and personal digital assistants (PDAs) are already intimate devices worn on the body, but there have been proposals for even tighter interfaces. Control of external devices through brain activity has been studied with some success for the last 40 years, although it remains a slow form of signaling (Wolpaw et al. 2000).

The most dramatic potential internal hardware enhancements are braincomputer interfaces. At present development is rapid both on the hardware side, where multielectrode recordings from more than 300 electrodes permanently implanted in the brain are currently state of the art, and on the software side, with computers learning to interpret the signals and commands (Carmena et al. 2003; Nicolelis et al. 2003; Shenoy et al. 2003). Early experiments on humans have shown that it is possible for profoundly paralyzed patients to control a computer cursor using just a single electrode (Kennedy and Bakay 1998) implanted in the brain and a 96 electrode prototype has been demonstrated (Hochberg et al. 2006). Prefrontal recordings enable choice selection with a bandwidth of 6.5 bits/s (Santhanam et al. 2006). Experiments in localized chemical release from implanted chips also suggest the possibility to use neural growth factors to promote patterned local growth and interfacing (Peterman et al. 2004).

Cochlear implants are already widely used, and there is ongoing research in artificial retinas (Alteheld et al. 2004) and functional electric stimulation for paralysis treatment (von Wild et al. 2002). These implants are mainly intended to ameliorate functional deficits and will hardly be attractive for healthy people in the foreseeable future. But the digital parts of the implant can in principle be connected to nearly any kind of software and external 
hardware (Hochberg et al. 2006). This would enable enhancing uses, such as access to software help, Internet, and virtual reality applications. It has been demonstrated that a healthy volunteer could control a robotic arm using tactile feedback, both in direct adjacency and remotely, as well as a wheelchair and perform simple neural communication with another implant (Warwick et al. 2003). Nondisabled people, however, would most likely achieve the same benefits through eyes, finger, and voice control. Neural implants are unlikely to become common enhancements until a "killer application" that cannot be achieved using external technology is found.

\section{COLLECTIVE ENHANCEMENT}

Much of human cognition is distributed across many minds and can be enhanced by developing more efficient forms of collaboration. Cooperative groups can detect deception better than individuals (Frank et al. 2004) and solve many problems better than equal numbers of individuals or even the best individuals (Laughlin et al. 2002; Kerr and Tindale 2004; Laughlin et al. 2006).

In general, the total ability of a group to perform a task increases with the size of the group as long as the members do not need to interact much. If they need to coordinate, the efficiency starts to drop as time has to be spent on coordination rather than work. In a densely connected group this eventually produces a situation where adding people reduces total performance. Reducing the density of the network by adding a hierarchy enables larger groups at the price of information bottlenecks. Social cognitive enhancement would act by either increasing the performance of individual group members (improving overall performance), improve their ability to coordinate (enabling larger groups), or improve the synergies generated by having multiple competencies.

This is an area ideally suited for embedding technologies that mediate group interactions. Virtual workspaces can enable improved pattern recognition (Hayne et al. 2003) and various forms of groupware attempts to facilitate collaboration. However, the greatest enhancements occur when very large groups can be facilitated: the World Wide Web and e-mail are among the most powerful kinds of cognitive enhancement software developed to date. Through the use of such social software, the distributed intelligence of large groups can be shared and harnessed for particular purposes (Surowiecki 2004).

Connected systems allow many people to collaborate in the construction of shared knowledge and solutions: the more individuals that connect, the more powerful the system becomes (Drexler 1991). The information is not just stored in the documents themselves but in their interrelations. When such interconnected information resources exist, automated systems, such as search engines (Kleinberg 1999), can extract a wealth of useful information from them. 
Lowered coordination costs enable larger groups to work on common projects. Such groups of shared interests, such as amateur journalist "bloggers" and open source programmers, have demonstrated that they can successfully complete large projects, such as online political campaigns (Drezner and Farrell 2004), the Wikipedia encyclopedia, and the Linux operating system. Systems for online collaboration can incorporate efficient error correction (Raymond 2001; Giles 2005), enabling incremental improvement of product quality over time.

An interesting variant of knowledge aggregation is prediction markets (also known as "information markets" or "idea futures markets"). Here participants trade in predictions of future events, and the prices of these bets tend to reflect the best information available on the probability of whether the events will occur (Hanson et al. 2003). Such markets appear to be self-correcting and resilient, and have been shown to outperform alternative methods of generating probabilistic forecasts, such as opinion polls and expert panels (Hanson et al. 2006).

Social cognitive enhancement represents a convergence of not only information and cognitive technology, but sociology, management, and epistemology. In order to be successful a wide variety of factors must come together, making deliberate design hard. It may not be a coincidence that the most successful systems have been the most open, enabling many different groups to experiment and discover whether they can get it to work for their goals. We seldom notice the vast number of failed attempts because they are overshadowed by the explosive growth of successful systems.

\section{NANOTECHNOLOGY}

Nanotechnology has so far not been applied to cognitive enhancement, which is unsurprising given its early state. However, in basic neuroscience research many nanotechnology applications are in use or close to use. Fluorescent nanodots are used in neuroscience research, where they enable direct observation of biomolecule interaction (Mitchell 2001; Weng and Ren 2006). Nanostructured scaffolds are explored in tissue engineering (Silva et al. 2004) and nerve regrowth (Ellis-Behnke et al. 2006). One near future application with great promise is nanostructured neural interfaces (Cheung et al. 2002). Providing the right surface would both help improve signal quality and reliability. Nanoelectrodes may also be threaded through the capillary system, enabling low-invasive neurointerfacing (Llinas et al. 2005). At the very least nanotechnology is an enabler of neuroscience research relevant for cognitive enhancement.

Another near-term application pursued with much commercial interest is drug delivery through nanostructures (Panyam and Labhasetwar 2003; Sahoo and Labhasetwar 2003) or controlled-release microchips (Santini et al. 1999; 
Grayson et al. 2003). This would enable precision pharmacology as well as possibly gene therapy.

It appears likely that as nanotechnology matures it will become an integral part of nearly all cognitive enhancement methods, be they light, powerful, and portable Internet interfaces or "smart drugs" that release modulators just when they are needed.

\section{CONVERGING METHODS}

As we have seen, many current applications already span disciplinary borders. Cognitive enhancement is based on the unity between the biological brain and the mind, and the unity between different kinds of information processing. Changing biological processes enables changes to the mind (and vice versa). Information processing is the same whether a brain or a computer does it. It hence lends itself well to the vision of converging technology.

Convergence enables many extensions of the current possibilities. As an example, take cortical plasticity. Currently it can be increased by attention, TMS, and drugs, such as amphetamines, in order to improve rehabilitation or learning. All three methods achieve the same goal using different means. Sustaining attention on a task requires motivation and can plausibly be improved using various forms of mental training; it has the benefit of being highly selective but requires significant effort. Current drugs are nonspecific and would increase plasticity in other cortical areas than the desired ones, besides effects on other parts of the brain. TMS is specific to a particular cortical area but requires training close in time and space to the stimulation equipment, and the task may be distributed over a large number of cortical areas.

Convergence easily suggests multiple ways these techniques can be improved. Improving TMS in terms of location specificity may be achieved by embedding micro- or nanoparticles close to the area to be modified (this may be particularly suitable for rehabilitation after neurosurgery) that augment the signal or help target it. By placing drugs within the particles they might promote nerve regrowth or dendritic sprouting, possibly triggered by external signals (Sershen and West 2002). The use of magnetic particles has already been explored to concentrate drugs to cancer tumors (Lubbe et al. 1996; Lubbe et al. 2001; Kim et al. 2006): the same mechanism could enable concentrating plasticity increasing drugs to the right cortical region even without surgery. More advanced particles or controlled-release microchips may able to sense local neuromodulator concentrations and regulate their drug release to amplify the selective effect of attention during training, making sure only the areas relevant to the training get affected.

On the macroscale, better sensor systems would enable improved understanding of individual brain chemistry, a prerequisite for finding the optimal 
combination of enhancer drugs. Wearable computing and other personal sensory devices enable the monitoring not only of body state but also behavior. This could enable personal data mining to find the individual optimum of, for example, blood glucose for different cognitive tasks by comparing it with monitored performance, and then based on measured glucose response to different meals suggest food intake that fits future scheduled demands. By pooling such individual data it would also be possible to make inferences on the general utility of different enhancer methods and the interactions between different factors. Rather than being a top-down academic study it might emerge as voluntary data sharing among users. This would represent an entirely new kind of epidemiological study. The difference is similar to the difference between the web-indices that seek to organize web sites into a predetermined subject hierarchy/ontology, and the current Web 2.0 experiments with generating "folksonomies" from locally tagged data (Shirky 2005). The challenges this form of "folk experimentation" poses in terms of data mining, scientific rigor (even if useful patterns are found the uncontrolled nature of the data may make strict interpretation hard), integrity concerns, and ownership concerns (are participants reimbursed for profitable discoveries?) are obviously great and may provide a very fruitful areas of research.

These scenarios are of course merely extrapolations at present, but demonstrate the synergistic potential of many current enhancement techniques.

\section{DISCUSSION}

Cognitive enhancement is already in widespread use, but not recognized as such. The morning coffee, the crossword, the e-mail program, and the cellphone are all part of our cognitive enhancement infrastructure. The new kinds of enhancement discussed in this article may appear unusual, futuristic, or problematic but will likely in time become as prosaic and accepted as the others.

It is easier to improve specialized abilities than general cognition. But the rewards are far greater for general cognition. It comes into play all the time, supporting many tasks - including uses we may not have thought of enhancing. Better memory may help education but it may also help remembering one's holiday memories and avoid forgetting keys. The overall societal impact of even a small increase in general cognitive function would likely be sizeable and desirable. Economic models of the loss caused by small intelligence decrements due to lead in drinking water predict significant effects of even a few points decrease (Salkever 1995; Muir and Zegarac 2001). Because the models are roughly linear for small changes, they can be inverted to estimate societal effects of improved cognition. The Salkever model estimates the increase in income due to one more IQ point to be $2.1 \%$ for men and $3.6 \%$ for women. (Herrnstein and Murray 1994) estimate that a 3\% increase in overall 
IQ would reduce the poverty rate by $25 \%$, males in jail by $25 \%$, high-school dropouts by $28 \%$, parentless children by $20 \%$, welfare recipients by $18 \%$, and out-of-wedlock births by $25 \%$.

Cognitive enhancement raises many ethical and social issues but also many practical challenges. Enhancements do have a price. In some cases it is a monetary price tag, but often it is a tradeoff between different abilities. Keeping awake using stimulants prevents the memory consolidation that would have taken place during sleep, and enhanced concentration ability may impair the ability to notice things in peripheral awareness. In some cases these tradeoffs can be predicted in terms of known biology or the evolutionary past of humans (Bostrom and Sandberg 2006), but often we will have to do an empirically based evaluation of what we individually value in a particular situation.

A major concern for all forms of enhancement is risk, both from enhancement itself and its effects (as well as its development in clinical trials). Enhancement users must decide when the benefits outweigh the potential risk, and how to estimate this on the basis of available information, personal goals, and their ways of life. These risks cannot always be accurately determined beforehand, nor may a user be able to defer to experts to judge whether the benefits are, to her, worth the risks. This poses a challenge to many current risk frameworks that are based on reducing the risk for the population at large: enhancement may be so individual and variable that it does not fit into a paternalistic framework. This challenge is further complicated because of the convergent nature of enhancement, which will bring different fields with conflicting risk concepts (e.g., medicine, education, and computing) into overlap. Developing a consistent, technology-independent risk management framework for converging technologies is an important task for the future, necessary for the eventual acceptance of general enhancement.

The reliability of research is also an issue. Many of the cognition-enhancing interventions show small effect sizes, which may necessitate very large epidemiological studies possibly exposing large groups to unforeseen risks.

One of the greatest challenges to developing effective cognitive enhancement is the current research model. Enhancers are tested within a laboratory setting for particular tasks. While this enables exact measurement and elimination of confounders, it does not test whether the enhancers aid real-life tasks and lifestyles. Ecological testing in real-life situations would be more relevant, but is far more expensive, time consuming, and hard to interpret. The "folk experimentation" scenario mentioned above might solve the first two problems but would likely worsen the third.

An interesting exception is military enhancement research, where studies in a more realistic (if still somewhat limited) setting are sometimes pursued. Civilian spin-offs from the current programs are likely, although the research ethics issues of military biomedical research are clearly nontrivial (cf. Pearn 2000; McManus et al. 2005 for a discussion of issues of captive subjects and informed consent). 
A major challenge in developing human enhancement technologies is the need for interdisciplinary understanding. The problems facing "neuroeducation" and groupware have already been mentioned. While narrowly focused technical work is necessary, it may be that some of the most fruitful approaches will consist in creatively combining and applying work from multiple disciplines. Seeing cognitive enhancement as one field and as a general goal, rather than as multitude of unrelated pursuits, may enable us to spot many promising research questions and enhancement opportunities that would otherwise be overlooked.

\section{REFERENCES}

Alteheld, N., G. Roessler, M. Vobig, and R. Walter. 2004. The retina implant new approach to a visual prosthesis. Biomedizinische Technik 49(4), 99-103.

AntAl, A., M.A. Nitsche, T.Z. KincSES, ET AL. 2004a. Facilitation of visuo-motor learning by transcranial direct current stimulation of the motor and extrastriate visual areas in humans. European Journal of Neuroscience 19(10), 2888-2892.

ANTAL, A., M.A. NitSChE, W. KRUSE, ET AL. 2004b. Direct current stimulation over V5 enhances visuomotor coordination by improving motion perception in humans. Journal of Cognitive Neuroscience 16(4), 521-527.

AsHBY, W.R. 1956. Introduction to Cybernetics. London: Chapman \& Hall.

BAILEY, C.H., D. BARTSCH, and E.R. KANDEL. 1996. Toward a molecular definition of long-term memory storage. Proceedings of the National Academy of Sciences of the United States of America 93(24), 13445-13452.

BAO, S.W., W.T. Chan, and M.M. MeRZENICH. 2001. Cortical remodelling induced by activity of ventral tegmental dopamine neurons. Nature 412(6842), 79-83.

BARCH, D.M. 2004. Pharmacological manipulation of human working memory. Psychopharmacology 174(1), 126-135.

Barnes, D.E., I.B. Tager, W.A. Satariano, and K. Yaffe. 2004. The relationship between literacy and cognition in well-educated elders. Journals of Gerontology Series a-Biological Sciences and Medical Sciences 59(4), 390-395.

BATEJAT, D.M., and D.P. LAGARDE. 1999. Naps and modafinil as countermeasures for the effects of sleep deprivation on cognitive performance. Aviation Space and Environmental Medicine 70(5), 493-498.

Blair, C., D. Gamson, S. Thorne, and D. BaKer. 2005. Rising mean IQ: cognitive demand of mathematics education for young children, population exposure to formal schooling, and the neurobiology of the prefrontal cortex. Intelligence 33(1), 93-106.

Bostrom, N., and A. SAndBerg. 2006. A Practical Approach to Human Enhancement. In J. Savulescu and N. Bostrom (eds.), Enhancement of Human Beings. Oxford: Oxford University Press, forthcoming.

BReitenstein, C., S. Wailke, S. Bushuven, ET AL. 2004. D-amphetamine boosts language learning independent of its cardiovascular and motor arousing effects. Neuropsychopharmacology 29(9), 1704-1714.

Butefisch, C.M., V. Khurana, L. Kopylev, and L.G. Cohen. 2004. Enhancing encoding of a motor memory in the primary motor cortex by cortical stimulation. Journal of Neurophysiology 91(5), 2110-2116. 
BuZAn, T. 1982. Use Your Head. London: BBC Books.

Caldwell, J.A., Jr., J.L. Caldwell, N.K. Smythe, 3rd, and K.K. Hall. 2000. A double-blind, placebo-controlled investigation of the efficacy of modafinil for sustaining the alertness and performance of aviators: a helicopter simulator study. Psychopharmacology (Berlin) 150(3), 272-282.

CAlef, T., M. PIEPER, and B. COFFEY. 1999. Comparisons of eye movements before and after a speed-reading course. Journal of the American Optometric Association 70(3), 171-181.

Cardinali, D.P., L.I. Brusco, S.P. Lloret, and A.M. Furio. 2002. Melatonin in sleep disorders and jet-lag. Neuroendocrinology Letters 23, 9-13.

Carmena, J.M., M.A. LebedeV, R.E. Crist, ET AL. 2003. Learning to control a brainmachine interface for reaching and grasping by primates. Plos Biology 1(2), 193-208.

CAtTell, R. 1987. Intelligence: It's Structure, Growth, and Action. New York: Elsevier Science.

Cheung, K.C., Y.-K. ChoI, T. Kubow, and L.P. LeE. 2002. Nanostructured Electrodes for Improved Neural Recording. Materials Research Society Spring 2002 Meeting, San Francisco, CA. In R.P. Manginell, J.T. Borenstein, L.P. Lee, and P.J. Hesketh (eds.), BioMEMS and Bionanotechnology MRS Proceedings, Vol. 729, Section U4.9. Warrendale, PA: Materials Research Society.

Cochran, G., J. Hardy, and H. Harpending. 2006. Natural History of Ashkenazi Intelligence. Journal of Biosocial Science 38(5), 659-693.

Craig, I., and R. Plomin. 2006. Quantitative trait loci for IQ and other complex traits: single-nucleotide polymorphism genotyping using pooled DNA and microarrays. Genes Brain and Behavior 5, 32-37.

Cropley, A.J. 2006. In praise of convergent thinking. Creativity Research Journal 18(3), 391-404.

DE Quervain, D.J.F., and A. PApassotiropoulos. 2006. Identification of a genetic cluster influencing memory performance and hippocampal activity in humans. Proceedings of the National Academy of Sciences of the United States of America 103(11), 4270-4274.

Diamond, M.C., R.E. Johnson, and C.A. Ingham. 1975. Morphological changes in young, adult and aging rat cerebral-cortex, hippocampus, and diencephalon. $B e-$ havioral Biology 14(2), 163-174.

Douglas, V.I., R.G. BarR, J. Desilets, and E. Sherman. 1995. Do high-doses of stimulants impair flexible thinking in attention-deficit hyperactivity disorder. Journal of the American Academy of Child and Adolescent Psychiatry 34(7), 877-885.

DREXLER, K.E. 1991. Hypertext publishing and the evolution of knowledge. Social Intelligence 1(2), 87-120.

Drezner, D.W., and H. Farrell. 2004. The Power And Politics Of Blogs. University of Chicago. Working paper. Available at http://www.utsc. utoronto.ca/ farrell/blogpaperfinal.pdf (accessed November 13, 2006).

Edelhoff, S., E.C. Villacres, D.R. Storm, and C.M. Disteche. 1995. Mapping of adenylyl-cyclase genes type-I, type-Ii, type-Iii, type-Iv, type-V and type-Vi in mouse. Mammalian Genome 6(2), 111-113.

Elliott, R., B.J. SahaKian, K. Matthews, ET AL. 1997. Effects of methylphenidate on spatial working memory and planning in healthy young adults. Psychopharmacology 131(2), 196-206. 
Ellis-BehnKe, R.G., Y.X. Liang, S.W. You, ET AL. 2006. Nano neuro knitting: peptide nanofiber scaffold for brain repair and axon regeneration with functional return of vision. Proceedings of the National Academy of Sciences of the United States of America 103(13), 5054-5059.

Engelbart, D.C. 1962. Augmenting Human Intellect: A Conceptual Framework. Menlo Park, CA: Stanford Research Institute.

ERICSSON, A.K. 2003. Exceptional memorizers: made, not born. Trends in Cognitive Sciences 7(6), 233-235.

FALls, W.A., M.J.D. MiserendinO, and M. DAVIS. 1992. Extinction of fear-potentiated startle - blockade by infusion of an nmda antagonist into the amygdala. Journal of Neuroscience 12(3), 854-863.

FAN, X., S. Sun, M. MCNEESE, and J. YEN. 2005a. Extending the recognition-primed decision model to support human-agent collaboration. $A A M A S^{\prime} 05$. Utrecht, Netherlands.

FAn, X., S. Sun, J. Yen, ET AL. 2005b. Collaborative RPD-enabled Agents Assisting The Three-Block Challenge in C2CUT. 2005 Conference on Behavior Representation in Modeling and Simulation (BRIMS 2005). Universal City, CA, May 16-19.

FARAH, M.J., J. Illes, R. COOK-DEEgAn, ET AL. 2004. Neurocognitive enhancement: what can we do and what should we do? Nature Reviews Neuroscience 5(5), 421-425.

FARrand, P., F. HuSSAIN, and E. HenNeSSY. 2002. The efficacy of the 'mind map' study technique. Medical Education 36(5), 426-431.

FeLTZ, D.L., and D.M. LANDERS. 1983. The effects of mental practice on motor skill learning and performance - a meta-analysis. Journal of Sport Psychology 5(1), $25-57$.

FLYNN, J.R. 1987. Massive IQ gains in 14 nations-what Iq tests really measure. Psychological Bulletin 101(2), 171-191.

Foster, J.K., P.G. LIDDER, and S.I. SUNRAM. 1998. Glucose and memory: fractionation of enhancement effects? Psychopharmacology 137(3), 259-270.

Frank, M.G., N. Paolantonio, T.H. Feeley, and T.J. Servoss. 2004. Individual and small group accuracy in judging truthful and deceptive communication. Group Decision and Negotiation 13(1), 45-59.

Fregni, F., P.S. Boggio, M. Nitsche, ET AL. 2005. Anodal transcranial direct current stimulation of prefrontal cortex enhances working memory. Experimental Brain Research 166(1), 23-30.

Freo, U., E. Ricciardi, P. Pietrini, ET AL. 2005. Pharmacological modulation of prefrontal cortical activity during a working memory task in young and older humans: a PET study with physostigmine. American Journal of Psychiatry 162(11), 2061-2070.

GILES, J. 2005. Internet encyclopaedias go head to head. Nature 438(7070), 900-901.

Gill, M., P. Haerich, K. Westcott, K.L. Godenick, and J.A. Tucker. 2006. Cognitive performance following modafinil versus placebo in sleep-deprived emergency physicians: a double-blind randomized crossover study. Academic Emergency Medicine 13(2), 158-165.

GLADSTONE, D.J., and S.E. BLACK. 2000. Enhancing recovery after stroke with noradrenergic pharmacotherapy: a new frontier? Canadian Journal of Neurological Sciences 27(2), 97-105.

Goldstein, L.B. 1999. Amphetamine-facilitated poststroke recovery. Stroke 30(3), 696-697.

Goswami, U. 2006. Neuroscience and education: from research to practice? Nature Reviews Neuroscience 7(5), 406-411. 
GOTTFREDSON, L.S. 1997. Why g matters: the complexity of everyday life. Intelligence 24(1), 79-132.

GotTFREDSON, L.S. 2004. Life, death, and intelligence. Journal of Cognitive Education and Psychology 4(1), 23-46.

Grayson, A.C.R., I.S. ChOI, B.M. TYler, ET AL. 2003. Multi-pulse drug delivery from a resorbable polymeric microchip device. Nature Materials 2(11), 767-772.

Greenough, W.T., and F.R. Volkmar. 1973. Pattern of Dendritic Branching in Occipital Cortex of Rats Reared in Complex Environments. Experimental Neurology 40(2), 491-504.

GulpinAR, M.A., and B.C. Yegen. 2004. The physiology of learning and memory: role of peptides and stress. Current Protein \& Peptide Science 5(6), 457-473.

HANSON, R., R. OPRE, and D. PORTER. 2006. Information aggregation and manipulation in an experimental market. Journal of Economic Behavior \& Organization 60(4), 449-459.

Hanson, R., C. Polk, J. Ledyard, and T. Ishikida. 2003.. The policy analysis market: an electronic commerce application of a combinatorial information market. $A C M$ Conference on Electronic Commerce 2003. New York: ACM Press.

HAYNE, S.C., C.A.P. SMith, and D. TURK. 2003. The effectiveness of groups recognizing patterns. International Journal of Human-Computer Studies 59(5), 523-543.

HEALEY, J., and R.W. PICARD. 1998. StartleCam: a cybernetic wearable camera. Second International Symposium on Wearable Computing, Pittsburgh, PA, Washington, DC: IEEE Computer Society.

Helland, I.B., L. SMith, K. SAAREM, ET AL. 2003. Maternal supplementation with verylong-chain n-3 fatty acids during pregnancy and lactation augments children's IQ at 4 years of age. Pediatrics 111(1), 39-44.

Herrnstein, R.J., and C. Murray. 1994. The Bell Curve. New York, NY: Free Press.

Heylighen, F. 2002a. Complexity and information overload in society: why increasing efficiency leads to decreasing control. Available at http://pcp.lanl.gov/Papers/Info-Overload.pdf (accessed November 13, 2006).

Heylighen, F. 2002b. Tackling complexity and information overload : intelligence amplification, attention economy and the global brain. Available at http://pcp.lanl.gov/Papers/Info-Overload.pdf (accessed November 13, 2006).

HochberG, L.R., M.D. SerRUYA, G.M. Friehs, ET AL. 2006. Neuronal ensemble control of prosthetic devices by a human with tetraplegia. Nature 442(7099), 164-171.

Hofmann, S.G., A.E. Meuret, J.A.J. Smits, ET AL. 2006. Augmentation of exposure therapy with D-cycloserine for social anxiety disorder. Archives of General Psychiatry 63(3), 298-304.

Hummel, F.C., and L.G. CoHen. 2005. Drivers of brain plasticity. Current Opinion in Neurology 18(6), 667-674.

IngVAR, M., J. AmBrosIngerson, M. DAVIS, ET AL. 1997. Enhancement by an ampakine of memory encoding in humans. Experimental Neurology 146(2), 553-559.

IVERSEN, S.D. 1998. The pharmacology of memory. Comptes Rendus De L Academie Des Sciences Serie Iii-Sciences De La Vie-Life Sciences 321(2-3), 209-215.

JaCkson, P.L., J. Doyon, C.L. Richards, and F. MAlouin. 2004. The efficacy of combined physical and mental practice in the learning of a foot-sequence task after stroke: a case report. Neurorehabilitation and Neural Repair 18(2), 106111.

Jebara, T., C. Eyster, J. Weaver, T. Starner, and A. Pentland. 1997. Stochasticks: augmenting the billiards experience with probabilistic vision and wearable computers. The International Symposium on Wearable Computers, Cambridge, MA, Washington, DC: IEEE Computer Society. 
Johnston, G. 2004. Healthy, wealthy and wise? A review of the wider benefits of education. New Zealand Treasury Working Paper 04/04. Wellington, New Zealand: The Treasury.

Kennedy, D.O., S. PACE, C. HASKell, ET AL. 2006. Effects of cholinesterase inhibiting sage (Salvia officinalis) on mood, anxiety and performance on a psychological stressor battery. Neuropsychopharmacology 31(4), 845-852.

KENNEDY, P.R., and R.A.E. BAKAY. 1998. Restoration of neural output from a paralyzed patient by a direct brain connection. Neuroreport 9(8), 1707-1711.

KeRR, N.L., and R.S. TINDALE. 2004. Group performance and decision making. Annual Review of Psychology 55, 623-655

Kilgard, M.P., and M.M. MerZENich. 1998. Cortical map reorganization enabled by nucleus basalis activity. Science 279(5357), 1714-1718.

KIM, J.S., T.J. YoON, B.G. KIM, ET AL. 2006. Toxicity and tissue distribution of magnetic nanoparticles in mice. Toxicological Sciences 89(1), 338-347.

KimberG, D.Y., M.D Esposito, and M.J. FARAH. 1997. Effects of bromocriptine on human subjects depend on working memory capacity. Neuroreport $8(16), 3581-$ 3585.

Kincses, T.Z., A. Antal, M.A. Nitsche, O. Bartfai, and W. Paulus. 2004. Facilitation of probabilistic classification learning by transcranial direct current stimulation of the prefrontal cortex in the human. Neuropsychologia 42(1), 113-117.

KISCHKA, U., T. KAMMER, S. MAIER, ET AL. 1996. Dopaminergic modulation of semantic network activation. Neuropsychologia 34(11), 1107-1113.

KLEINBERG, J.M. 1999. Authoritative sources in a hyperlinked environment. Journal of the ACM 46(5), 604-632.

Kobayashi, M., S. Hutchinson, H. Theoret, G. Schlaug, and A. Pascual-Leone. 2004. Repetitive TMS of the motor cortex improves ipsilateral sequential simple finger movements. Neurology 62(1), 91-98.

Korol, D.L., and P.E. Gold. 1998. Glucose, memory, and aging. American Journal of Clinical Nutrition 67(4), 764s-771s.

LASHLEY, K.S. 1917. The effects of strychnine and caffeine upon rate of learning. Psychobiology 1, 141-169.

LAughlin, P.R., B.L. Bonner, and A.G. Miner. 2002. Groups perform better than the best individuals on Letters-to-Numbers problems. Organizational Behavior and Human Decision Processes 88(2), 605-620.

Laughlin, P.R., E.C. Hatch, J.S. Silver, and L. BoH. 2006. Groups perform better than the best individuals on letters-to-numbers problems: effects of group size. Journal of Personality and Social Psychology 90(4), 644-651.

LEE, E.H.Y., and Y.L. MA. 1995. Amphetamine enhances memory retention and facilitates norepinephrine release from the hippocampus in rats. Brain Research Bulletin 37(4), 411-416.

LICKLIDER, J.C.R. 1960. Man-Computer Symbiosis. IRE Transactions on Human Factors in Electronics HFE 1, 4-11.

LiEBERMAN, H.R. 2001. The effects of ginseng, ephedrine, and caffeine on cognitive performance, mood and energy. Nutrition Reviews 59(4), 91-102.

Llinas, R.R., K.D. Walton, M. NaKao, I. Hunter, and P.A. ANQuetil. 2005. Neurovascular central nervous recording/stimulating system: using nanotechnology probes. Journal of Nanoparticle Research 7(2), 111-127.

Lorrayne, H. 1996. Page a Minute Memory Book. New York: Ballantine Books.

Lubbe, A.S., C. Alexiou, and C. Bergemann. 2001. Clinical applications of magnetic drug targeting. Journal of Surgical Research 95(2), 200-206. 
Lubbe, A.S., C. Bergemann, H. Riess, Et AL. 1996. Clinical experiences with magnetic drag targeting: a phase I study with 4'-epidoxorubicin in 14 patients with advanced solid tumors. Cancer Research 56(20), 4686-4693.

LYNCH, G. 1998. Memory and the brain: unexpected chemistries and a new pharmacology. Neurobiology of Learning and Memory 70(1-2), 82-100.

LYNCH, G. 2002. Memory enhancement: the search for mechanism-based drugs. Nature Neuroscience 5, 1035-1038.

Maguire, E.A., E.R. VAlEnTine, J.M. Wilding, and N. KAPUR. 2003. Routes to remembering: the brains behind superior memory. Nature Neuroscience 6(1), 90-95.

MAnN, S. 1997. Wearable computing: a first step toward personal imaging. Computer $30(2), 25-31$.

MANN, S. 2001. Wearable computing: toward humanistic intelligence. IEEE Intelligent Systems 16(3), 10-15.

Mann, S., and H. Niedzviecki. 2001. Cyborg: Digital Destiny and Human Possibility in the Age of the Wearable Computer. Toronto, Canada: Doubleday Canada.

Marshall, L., M. Molle, M. Hallschmid, and J. Born. 2004. Transcranial direct current stimulation during sleep improves declarative memory. Journal of $\mathrm{Neu}$ roscience 24(44), 9985-9992.

McManus, J., S.G. Mehta, A.R. McClinton, R.A. De Lorenzo, and T.W. Baskin. 2005. Informed consent and ethical issues in military medical research. Academic Emergency Medicine 12(11), 1120-1126.

MECK, W.H., and C.L. WiLLIAMS. 2003. Metabolic imprinting of choline by its availability during gestation: implications for memory and attentional processing across the lifespan. Neuroscience and Biobehavioral Reviews 27(4), 385-399.

Meck, W.H., R.A. SMith, and C.L. WiLliams. 1988. Prenatal and postnatal choline supplementation produces long-term facilitation of spatial memory. Developmental Psychobiology 21(4), 339-353.

Mehta, M.A., A.M. Owen, B.J. Sahakian, et AL. 2000. Methylphenidate enhances working memory by modulating discrete frontal and parietal lobe regions in the human brain. Journal of Neuroscience 20(6), RC65.

Meikle, A., L.M. Riby, and B. Stollery. 2005. Memory processing and the glucose facilitation effect: the effects of stimulus difficulty and memory load. Nutritional Neuroscience 8(4), 227-232.

Mellott, T.J., C.L. Williams, W.H. Meck, and J.K. Blusztajn. 2004. Prenatal choline supplementation advances hippocampal development and enhances MAPK and CREB activation. FASEB Journal 18(1), 545-547.

Minninger, J. 1997. Total Recall. How to Boost Your Memory Power. New York: MJF Books.

MitCHELL, P. 2001. Turning the spotlight on cellular imaging — advances in imaging are enabling researchers to track more accurately the localization of macromolecules in cells. Nature Biotechnology 19(11), 1013-1017.

MondADORI, C. 1996. Nootropics: preclinical results in the light of clinical effects; comparison with tacrine. Critical Reviews in Neurobiology 10(3-4), 357-370.

Muir, T., and M. ZEGARAC. 2001. Societal costs of exposure to toxic substances: economic and health costs of four case studies that are candidates for environmental causation. Environmental Health Perspectives 109, 885-903.

Muller, U., N. Steffenhagen, R. Regenthal, and P. Bublak. 2004. Effects of modafinil on working memory processes in humans. Psychopharmacology 177(1-2), 161-169. 
Myrick, H., R. Malcolm, B. TAYlor, and S. LARowe. 2004 Modafinil: preclinical, clinical, and post-marketing surveillance - a review of abuse liability issues. Annals of Clinical Psychiatry 16(2), 101-109.

NAVA, E., D. LANDAU, S. BRody, L. Linder, and H. Schachinger. 2004. Mental relaxation improves long-term incidental visual memory. Neurobiology of Learning and Memory 81(3), 167-171.

NeISSER, U. 1997. Rising scores on intelligence tests. American Scientist 85(5), 440447.

Newhouse, P.A., A. Potter, and A. Singh. 2004. Effects of nicotinic stimulation on cognitive performance. Current Opinion in Pharmacology 4(1), 36-46.

Nicolelis, M.A.L., D. Dimitrov, J.M. Carmena, ET AL. 2003. Chronic, multisite, multielectrode recordings in macaque monkeys. Proceedings of the National Academy of Sciences of the United States of America 100(19), 11041-11046.

Nilsson, M., E. Perfilieva, U. Johansson, O. Orwar, and P.S. EriKsson. 1999. Enriched environment increases neurogenesis in the adult rat dentate gyrus and improves spatial memory. Journal of Neurobiology 39(4), 569-578.

Nitsche, M.A., A. Schauenburg, N. Lang, et AL. 2003. Facilitation of implicit motor learning by weak transcranial direct current stimulation of the primary motor cortex in the human. Journal of Cognitive Neuroscience 15(4), 619626.

Norlander, T., and R. GuSTAFsON. 1996. Effects of alcohol on scientific thought during the incubation phase of the creative process. The Journal of Creative Behavior 30(4), 231-248.

NORLANDER, T., and R. GUSTAFSON. 1997. Effects of alcohol on picture drawing during the verification phase of the creative process. Creativity Research Journal 10(4), $355-362$.

Nyberg, L., J. SAndBlom, S. Jones, ET AL. 2003. Neural correlates of training-related memory improvement in adulthood and aging. Proceedings of the National Academy of Sciences of the United States of America 100(23), 13728-13733.

PANYAM, J., and V. LABHASETWAR. 2003. Biodegradable nanoparticles for drug and gene delivery to cells and tissue. Advanced Drug Delivery Reviews 55(3), 329-347.

Pascual-Leone, A., F. Tarazona, J. Keenan, et AL. 1999. Transcranial magnetic stimulation and neuroplasticity. Neuropsychologia 37(2), 207-217.

Patten, B.M. 1990. The history of memory arts. Neurology 40(2), 346-352.

PEARn, J. 2000. Medical ethics surveillance in the armed forces. Military Medicine 165(5), 351-354.

Peterman, M.C., J. Nooland, M.S. Blumenkranz, and H.A. Fishman. 2004. Localized chemical release from an artificial synapse chip. Proceedings of the National Academy of Sciences of the United States of America 101(27), 9951-9954.

Petersson, K.M., A. Reis, S. AsKelof, ET AL. 2000. Language processing modulated by literacy: a network analysis of verbal repetition in literate and illiterate subjects. Journal of Cognitive Neuroscience 12(3), 364-382.

PitMAn, R.K., K.M. SANDERS, R.M. ZuSMAN, ET AL. 2002. Pilot study of secondary prevention of posttraumatic stress disorder with propranolol. Biological Psychiatry 51(2), 189-192.

Power, A.E., A. Vazdarjanova, and J.L. McGaugh. 2003. Muscarinic cholinergic influences in memory consolidation. Neurobiology of Learning and Memory 80(3), 178-193.

Raine, A., C. Reynolds, P.H. Venables, and S.A. Mednick. 2002. Stimulation seeking and intelligence: a prospective longitudinal study. Journal of Personality and Social Psychology 82(4), 663-674. 
RaYmond, E.S. 2001. The Cathedral and the Bazaar. Cambridge, MA: O'Reilly.

Ressler, K.J., B.O. Rothbaum, L. TAnnenbaum, et AL. 2004. Cognitive enhancers as adjuncts to psychotherapy-use of D-cycloserine in phobic individuals to facilitate extinction of fear. Archives of General Psychiatry 61(11), 11361144.

RHODES, B., and T. STARNER. 1996. Remembrance agent: a continuously running automated information retrieval system. The First International Conference on The Practical Application Of Intelligent Agents and Multi Agent Technology (PAAM '96). London (April 1996), pp. 486-495.

Routtenberg, A., I. Cantallops, S. Zaffuto, P. Serrano, and U. Namgung. 2000. Enhanced learning after genetic overexpression of a brain growth protein. Proceedings of the National Academy of Sciences of the United States of America 97(13), 7657-7662.

Rusted, J.M., S. Trawley, J. Heath, G. Kettle, and H. Walker. 2005. Nicotine improves memory for delayed intentions. Psychopharmacology (Berlin) 182(3), $355-365$.

SAHOO, S.K., and V. LABHASETWAR. 2003. Nanotech approaches to delivery and imaging drug. Drug Discovery Today 8(24), 1112-1120.

SALKEVER, D.S. 1995. Updated estimates of earnings benefits from reduced exposure of children to environmental lead. Environmental Research 70(1), 1-6.

Santhanam, G., S.I. Ryu, B.M. Yu, A. Afshar, and K.V. Shenoy. 2006. A highperformance brain-computer interface. Nature 442(7099), 195-198.

SANTINI, J.T., M.J. CimA, and R. LANGER. 1999. A controlled-release microchip. Nature 397(6717), 335-338.

Schillerstrom, J.E., M.S. Horton, and D.R. Royall. 2005. The impact of medical illness on executive function. Psychosomatics 46(6), 508-516.

SCHNEIDER, J.S., M.H. LeE, D.W. ANDERSON, L. ZuCK, and T.I. LIDSKY. 2001. Enriched environment during development is protective against lead-induced neurotoxicity. Brain Research 896(1-2), 48-55.

Sellen, A.J., G. Louie, J.E. Harris, and A.J. Wilkins. 1996. What brings intentions to mind? An in situ study of prospective memory. Rank Xerox Research Centre Technical Report EPC-1996-104. Cambridge, UK: Rank Xerox Research Centre.

SERShEN, S., and J. WeSt. 2002. Implantable, polymeric systems for modulated drug delivery. Advanced Drug Delivery Reviews 54(9), 1225-1235.

Shenoy, K.V., D. Meeker, S.Y. CAO, ET AL. 2003. Neural prosthetic control signals from plan activity. Neuroreport 14(4), 591-596.

SHIRKY, C. 2005. Ontology is overrated: categories, links, and tags. Available at http://www.shirky.com/writings/ontology_overrated.html (accessed November 13, 2006).

Silva, G.A., C. Czeisler, K.L. Niece, ET AL. 2004. Selective differentiation of neural progenitor cells by high-epitope density nanofibers. Science 303(5662), 13521355.

SingletARY, B.A., and T. STARnER. 2000. Symbiotic interfaces for wearable face recognition. HCII2001 Workshop On Wearable Computing, New Orleans, LA.

Smith, A., C. Brice, J. Nash, N. Rich, and D.J. NutT. 2003. Caffeine and central noradrenaline: effects on mood, cognitive performance, eye movements and cardiovascular function. Journal of Psychopharmacology 17(3), 283292.

Snyder, A., T. Bossomaier, and D.J. Mitchell 2004. Concept formation: 'object' attributes dynamically inhibited from conscious awareness. Journal of Integrative Neuroscience 3(1), 31-46. 
Snyder, A.W., E. Mulcahy, J.L. Taylor, ET AL. 2003. Savant-like skills exposed in normal people by suppressing the left fronto-temporal lobe. Journal of Integrative Neuroscience 2(2), 149-158.

Soetens, E., R. Dhooge, and J.E. Hueting. 1993. Amphetamine enhances humanmemory consolidation. Neuroscience Letters 161(1), 9-12.

Soetens, E., S. CASAer, R. DhoOge, and J.E. Hueting. 1995. Effect of amphetamine on long-term retention of verbal material. Psychopharmacology 119(2), 155-162.

Solanto, M.V., and E.H. Wender. 1989. Does methylphenidate constrict cognitivefunctioning. Journal of the American Academy of Child and Adolescent Psychiatry 28(6), 897-902.

Stroemer, R.P., T.A. Kent, and C.E. Hulsebosch. 1998. Enhanced neocortical neural sprouting, synaptogenesis, and behavioral recovery with D-amphetamine therapy after neocortical infarction in rats. Stroke 29(11), 2381-2393.

Surowiecki, J. 2004. The Wisdom of Crowds: Why the Many Are Smarter Than the Few and How Collective Wisdom Shapes Business, Economies, Societies and Nations. London: Random House.

Tan, D.P., Q.Y. Liu, N. KoshiYa, H. Gu, and D. Alkon. 2006. Enhancement of longterm memory retention and short-term synaptic plasticity in cbl-b null mice. Proceedings of the National Academy of Sciences of the United States of America 103(13), 5125-5130.

TANG, Y.P., E. Shimizu, G.R. Dube, ET AL. 1999. Genetic enhancement of learning and memory in mice. Nature 401(6748), 63-69.

Teitelman, E. 2001. Off-label uses of modafinil American Journal of Psychiatry $158(8), 1341-1341$.

Tieges, Z., K. Richard Ridderinkhof, J. Snel, and A. KoK. 2004. Caffeine strengthens action monitoring: evidence from the error-related negativity. Brain Research. Cognitive Brain Research. 21(1), 87-93.

TOMPOROWSKI, P.D. 2003. Effects of acute bouts of exercise on cognition. Acta Psychologica 112(3), 297-324.

Trachtenberg, J. 2000. The Trachtenberg Speed System of Basic Mathematics. London: Souvenir Press.

Turner, D.C., T.W. RobBins, L. Clark, et AL. 2003. Cognitive enhancing effects of modafinil in healthy volunteers. Psychopharmacology 165(3), 260-269.

VAYNMAN, S., and F. GOMEZ-PINILLA. 2005. License to run: exercise impacts functional plasticity in the intact and injured central nervous system by using neurotrophins. Neurorehabilitation and Neural Repair 19(4), 283-295.

von Wild, K., P. Rabischong, G. Brunelli, M. Benichou, and K. Krishnan. 2002. Computer added locomotion by implanted electrical stimulation in paraplegic patients (SUAW). Acta Neurochirurgica Supplementum 79, 99104.

Walsh, R.N., O.E. Budtz-Olsen, J.E. Penny, and R.A. Cummins. 1969. The effects of environmental complexity on the histology of the rat hippocampus. The Journal of Comparative Neurology 137(3), 361-365.

Wang, H.B., G.D. Ferguson, V.V. Pineda, P.E. Cundiff, and D.R. Storm. 2004. Overexpression of type-1 adenylyl cyclase in mouse forebrain enhances recognition memory and LTP. Nature Neuroscience 7(6), 635-642.

WARburton, D.M. 1992. Nicotine as a cognitive enhancer. Progress in NeuroPsychopharmacology and Biological Psychiatry 16(2), 181-191.

WARWICK, K., M. GASSON, B. HutT, ET AL. 2003. The application of implant technology for cybernetic systems. Archives of Neurology 60(10), 1369-1373. 
WeI, F., G.D. WANG, G.A. Kerchner, Et AL. 2001. Genetic enhancement of inflammatory pain by forebrain NR2B overexpression. Nature Neuroscience 4(2), 164169.

WeISER, M. 1991. The computer for the twenty-first century. Scientific American 265(3), 94-110.

WENG, J.F., and J.C. REN. 2006. Luminescent quantum dots: a very attractive and promising tool in biomedicine. Current Medicinal Chemistry 13(8), 897-909.

WENK, G. 1989. An hypothesis on the role of glucose in the mechanism of action of cognitive enhancers. Psychopharmacology 99, 431-438.

Whalley, L.J., and I.J. DeAry. 2001. Longitudinal cohort study of childhood IQ and survival up to age 76. British Medical Journal 322(7290), 819-822.

White, H.A., and P. SHAH. 2006. Uninhibited imaginations: creativity in adults with attention-deficit/hyperactivity disorder. Personality and Individual Differences 40(6), 1121-1131.

Wilkinson, L., A. Scholey, and K. Wesnes. 2002. Chewing gum selectively improves aspects of memory in healthy volunteers. Appetite 38(3), 235-236.

WINDER, R., and J. BORRILL. 1998. Fuels for memory: the role of oxygen and glucose in memory enhancement. Psychopharmacology 136(4), 349-356.

Winship, C., and S. Korenman. 1997. Does staying in school make you smarter? The effect of education on IQ in The Bell Curve. Pp. 215-234 in B. Devlin, S.E. Fienberg, and K. Roeder (eds.), Intelligence, Genes, and Success: Scientists Respond to The Bell Curve. New York: Springer.

Wolpaw, J.R., N. Birbaumer, W.J. HEETDERKS, ET AL. 2000. Brain-computer interface technology: a review of the first international meeting. IEEE Transactions on Rehabilitation Engineering 8(2), 164-173.

YATES, F. 1966. The Art of Memory. Chicago: University of Chicago Press.

ZHOU, M.F., and J.B. SuszKIw. 2004. Nicotine attenuates spatial learning lead deficits induced in the rat by perinatal exposure. Brain Research 999(1), 142-147. 